Indonesian Journal of EFL and Linguistics

Vol. 5 No. 1, 2020

eISSN: 2503-4197, pISSN: 2527-5070

www. indonesian-efl-journal.org

\title{
The Departure Point in Raising Teacher's Awareness toward the Atmosphere of Lingua Franca Case
}

\author{
Ambar Jati \\ Universitas Sebelas Maret \\ e-mail: ambarjati6@gmail.com \\ Endang Fauziati \\ Universitas Muhammadiyah Surakarta \\ e-mail: endang.fauziati@ums.ac.id \\ Sri Samiati Tarjana \\ Universitas Sebelas Maret \\ e-mail: msrisamiati44@gmail.com
}

\begin{abstract}
:
There has been growing attentiveness in the English teaching literature of the prominence of English as Lingua Franca (ELF). The foremost position of English as language of global citizen should be raised up in the communication traffic in the world. Research under the case study design had been done to reveal teacher's belief and their responses in the wave of English as Lingua Franca features in expanding circle, Indonesia. The researchers conducted the study at an Indonesian International School in Surakarta which involved two teachers as the participants by employing interview and unstructured questionnaire to collect the data. The result evidently showed that teachers in expanding circle were aware about the evolvement of English as Lingua Franca in the world. They believed that the features of English as Lingua Franca (ELF) are unproblematic as long as it does not change the fundament of their utterances. Henceforth, the teachers support the lexico-grammar features of ELF. In their speaking class, teachers give tolerance to the students who appearing these
\end{abstract}


Ambar Jati, Endang Fauziati and Sri Samiati Tarjana

features in their classroom interaction. Furthermore, the result of this research could inspire other teachers to be more aware toward the evolvement of ELF, so that they could integrate and apply the relevancy of ELF in teaching learning process.

Keywords: English as lingua franca, expanding circle, teacher's belief

\section{INTRODUCTION}

Unprecedented globalization in $21^{\text {st }}$ century triggers global spread of English dynamically (Seidlhofer, 2006). English is no longer used by Native Speakers but also used by global citizen. Consequently, most interaction in English occurred among nonnative speakers. As Crystal (2003) said that twenty five percent of English user is Native Speaker (NS). Through this emergence, the term English as Lingua Franca should be raised up in the communication traffic throughout the world. Recently, Philipson (2008) introduced the term "lingua frankensteina" that has the meaning as neutral language integrating in the youth culture.

Regarding the status of English in the world, Kachru (1985) highlights the concept of the use of English into 3 circles, namely inner circle consisting English as Native Language (e.g. UK), outer circle involving English as Second Language (e.g. Singapore) and expanding circle (e.g. Indonesia) including English as Foreign Language. Furthermore, the position of English as Lingua Franca (ELF) is under the expanding circle's umbrella. Therefore, many experts reveal the existence of English as Lingua Franca. The first concept, it is outlined that English as Lingua Franca (ELF) may be a contact language between people that share neither culture nor native tongue, and for whom English is that the chosen foreign language of communication (Firth, 1996).

Similarly, Seidlhofer (2004) also argues that English is as communicative medium choice which is used among speakers of diverse first language. In other words, ELF does not depend on the rule of Native Speaker. It is shaped and shared by non-native speakers (Seidlhofer, 2006). In everyday communication, million people interact in ELF usage to gain successful communication. Globally, of course, ELF creates many different forms. So, in consensus, there must be substantial core of vocabulary, grammar, and pronunciation that makes this possible (Seidlhofer, 2006).

Furthermore, Jenkins (2000) additionally also declares that ELF is employed in context during which speakers with totally different L1 (mostly, from the expanding circle) use it as their means that to speak with others. He added that ELF is another to EFL instead of a replacement for it, and it depends on speaker (learner)'s potential wants and preferences. In addition, Görlach (1990) also stated that ELF is formulas as broken and deficient form of English, however there is no risk of deviant usages of the standard native speakers. 
In Indonesia context, English has status as English as Foreign Language (hereafter, EFL). The aim of gaining knowledge in English for non-native speakers posit to accomplish cultural and linguistic assimilation in L1 society. Moreover, departures from these norms are the result of L1 interference or poor competence (BELZ, 2002). Different from this perspective, ELF has emergent strategies and specific features rather than seeing interference. The most unique concept that there is certain expression in L1 norms that would be 'error', but it is actually unproblematic and no obstacle to gain successful interaction through ELF (Seidlhofer, 2006).

Based on those perspectives, the researchers challenge to investigate the existence of ELF deeply in classroom interaction. Furthermore, it focuses more on teacher's awareness toward ELF. In preliminary research of classroom interaction, the researchers found the unique case in an Indonesian International School which is related to ELF. In the interaction, a student says,

\section{"I think that Sheren which is absent today."}

This expression indicates the Lingua Franca indicators proposed by Seidlhofer (2004), namely interchangeably using relative pronoun. The teacher argues that it can be acceptable in spoken form, but it is not desirable. So, the teacher will give corrective feedback to get improvement. The teacher adds that it is unproblematic in the classroom interaction.

From those cases, the teacher's viewpoints become pivotal in evolving English as Lingua Franca term. In English classroom, teachers contributes the biggest impact for English learners. Subsequently, there has been growing interest in the English teaching literature of the status of ELF such as confirming teacher's belief. According to Richards, et.al. (2001), teacher's belief is viewed as the result of teachers' selfconstruction. It means that teachers have their own process on their understanding toward the phenomena around them, and their views are shaped in their mind. While, Pajares (1992) stated that exploring teacher's belief is crucial to enhance teacher's development and teaching practice.

A subsequent research by Bayyurt et.al (2019) revealed about English language teachers' belief of ELF in multilingual and multicultural frameworks. It discovered that although teachers were aware toward EFL, but they were hesitant about its applicability in their own teaching context. The latest study, Asakereh et.al (2019) also investigated pre service teachers' belief in Iranian context. The results of the study revealed that the participants indicate further predisposition toward native speaker although the flexibility of ELF is reflected in their teaching.

Current study by Fazilatfar and Rahatloo (2018) investigated Iranian teacher trainees' attitude towards the current wave of English as Lingua Franca. In Iran context, it revealed that Iranian teacher's trainee indicates ambivalence toward the existing of ELF norms. The result shows that teachers have strong dependency toward Native Speaker (NS) norms. Other fascinating cases come from Luo (2017) that deeply 
investigated the teacher's perception of teaching ELF in expanding circle, especially Taiwan. In line with this research, he also revealed the challenges faced by teachers in integrating ELF instruction. He revealed that teachers are mindful of ELF ideas, but they moreover conform the prominence of Native Speaker (NS) norms in English teaching.

Furthermore, Nagy (2016) also investigated the research in this field. He attempted to reveal ELF and its repercussions in the instruction of English as Foreign Language (EFL). It revealed that LFC contains phonology, morpho-syntactic, and pragmatic element in ELF interaction. In this term, the researcher stated that ELF cannot change EFL, because ELF is not a language alternative, however it is a communication device. While, it was found that the finding of ELF research has great relevance to teaching EFL. Similarly, Curran and Chern (2017) investigated teacher trainees' attitude headed for EFL context. Based on the result, many participants expressed many terms to support the characteristic of ELF, such as using English for real communication, respecting all varieties in English, willingness to study more about intercultural communication.

Currently, many studies were also conducted in expanding circle, such as in the Iran and Taiwan context. Therefore, the study fulfilled the gap by investigating ELF in Indonesia environment. This research aims to reveal English teacher's belief in ELF and the reasons that English teachers give to their responses toward the realization of ELF's features. It is interested, because the researchers conduct it in an Indonesian international school. It is evident that this present research has not been examined yet. Furthermore, this becomes novelty of this current study. The researchers hope that this research can give contribution to the enhancement of English as Lingua Franca. Furthermore, it can be a departure point to raise awareness to the lexico-grammar features of ELF to accomplish the objective of communication.

To sum up, the researchers identify the problem as follow:

a. What is English teacher's belief in English as Lingua Franca in relation to Lexicogrammar case?

b. What reasons do English teachers give to their response to the realization of Lexicogrammar of ELF in classroom communication?

\section{LITERATURE REVIEW}

\subsection{Teacher's Belief}

Teacher's viewpoints become pivotal in evolving English as Lingua Franca term. In English class, teachers contribute the biggest impact for English learners. Subsequently, there has been growing interest in the English teaching literature of the status of ELF such as confirming teacher's belief. According to Richards, et.al. (2001), teacher's belief is viewed as the result of teachers' self-construction. It means that teachers have their own process on their understanding toward the phenomena around them, and their views are shaped in their mind. While, Pajares (1992) stated that 
exploring teacher's belief is crucial to enhance teacher's development and teaching practice.

Teacher belief develops gradually within teacher's teaching career. It is in line with Farrell (2011) who states that teacher's belief is constructed within such interaction over a teacher's career. Meanwhile, Borg (2001) explains that teacher's belief is reflected in classroom practices. It indicates that as long as teachers develop their career, their belief can be highlighted by observing the classroom practices that they conduct. In formulating the concept of teacher belief, it is important to investigate the sources of teacher belief. In the earlier, Richards and Lokhart (1996) suggested the bases of teachers' beliefs. Those are teacher's practice as learners, practice from teaching, teacher's behaviour, expectation or demand from the school, government, parents and local civilization, and education or study-based principle.

\subsection{English as Lingua Franca}

There has been growing interest in English of teaching literature of the identity of English as Lingua Franca (hereafter ELF). Henceforth, based on the grand theory, English as Lingua Franca (ELF) could be contact language between individuals who share not one or the other native tongue nor culture, and for whom English is the selected foreign language of interaction (Firth, 1996). In addition, English as Lingua Franca is characterized as a device of communication between speakers who do not share their first language, both among non-native speakers and when native speakers talk to non-native speakers (Bjorge, 2012).Well-known expert like Seidlhofer also contributed in the enhancement of ELF. Similarly, Seidlhofer (2004) argued that ELF is English as communicative tool of choice which is used among speakers of different first languages.

Furthermore, Heberland (2011) argues that ELF speakers speak in deviance from L1 norm. Seidlhofer (2006) emphasizes that the usage of definite features in ELF which is error in L1 norm commonly do not appear to be problematical and do not chunk communicative success. Seidlhofer (2006) presents the features of ELF interlocutors from many different first language backgrounds. Those are as follow:

1. Omission of the third-person singular of present tense;

2. Exchangeable use of the relative pronouns who and which;

3. Improper use of tags in questions;

4. Missing out definite and indefinite articles;

5. Usage of dismissed prepositions;

6. Common use of certain semantically-versatile, broad-spectrum verbs;

7. Using that-clauses as a replacement for of infinitive structures, and

8. Overdoing explicitness. 
Ambar Jati, Endang Fauziati and Sri Samiati Tarjana

\section{RESEARCH METHODOLOGY}

\subsection{Participants}

This study was categorized as qualitative study in the form of intrinsic case study. This case study explores teacher's belief in English as Lingua Franca at an Indonesian International School, because the researcher found unique case which happened in the classroom interaction related to English as Lingua Franca (ELF). According to Yin (2018), case study is an experiential method that reveals current phenomena (the case) in detailed within real-world setting, and it is not clear evident yet between phenomenon and context. He added that case study design is chosen when (1) the research questions are "how" and "why" questions, (2) it is contemporary phenomena, (3) it has little control over behavioral events.

Afterwards, two English teachers were participated in this research. The research was conducted at an Indonesian international school in Surakarta, Indonesia. It is a private school in Surakarta, Indonesia. In this research, ethical consideration was established in the process of formulating research objectives. So that, there was an agreement that the researcher would not publish the school name regarding to the result of this research. Furthermore, the participants were experienced teachers who have been teaching English for five years and they teach speaking subject. They were chosen to participate in this research, because teachers in speaking subject were related to classroom communication that was closed to the phenomena of English as Lingua Franca. In addition, the teachers also teach students that use English as daily communication at school, because it is an international school context. Moreover, the researchers found the phenomena of ELF in their classroom interaction. As participants, they were graduated from a private university and state university in Indonesia. Hereafter, the participants were called as T1 for the first participant, and T2 for the second participant. T1 is 28 years old, and T2 is 29 years old.

\subsection{Instruments}

In obtaining the data, the researchers carried out semi-structured interview and unstructured questionnaire. The researchers took the data from two English teachers. Those designs were to obtain the data about teacher's belief in English as Lingua Franca (ELF) and their response toward the realization of ELF features in classroom interaction. The interview and questionnaire designs were inspired from the theory of Seidlhofer (2004). The researchers recorded and transcribed the interview attentively to gain the verified data. The questionnaire was to strengthen and to deepen the result of the interview.

\subsection{Data Analysis Procedures}

The data in this study were in the form of information correlated to teacher's belief and their response in English as Lingua Franca. In examining the data, the researchers employed a facts evaluation approach from Miles, Huberman, and Saldana (2018). The stages involved in that design were data condensation, data display and data 
conclusion. First, the condensation of data was portrayed by writing sum-ups, coding, emerging themes, producing categories, and writing systematic memos. After that, the result of interview and survey was portrayed descriptively, so the result related to this research's issue can be revealed in evidence. In the last step, the researchers drew initial conclusion and verified the data.

\section{FINDINGS AND DISCUSSION}

This section elucidates both findings and discussion related to teacher's belief and their response in ELF. It was presented into several aspects as follows:

\subsection{English Teacher's Belief in English as Lingua Franca}

Revealing the understanding of the teacher toward the existence of English as Lingua Franca is significant to achieve the goal of communication. Teachers viewed these terms differently. Generally, teachers got the point of the ELF concept. Teachers were aware toward the term "Lingua Franca". The first participant (T1) viewed ELF as the use of English as a usual language among speakers who do not use English as native language in their country. In addition, the second participant (T2) said that ELF is the way of communicating between individuals of diverse native languages. T1 expressed her concept as follows:

"I think it is about the use of English as a common language between speakers who do not use English as native language in their country."

Teacher 1

T2 also had similar point as T1 as follows:

"When I hear term English as Lingua Franca means I hear many languages in a community that is being spoken. Way of communicating between people of different native languages."

Teacher 2

The main concern on $\mathrm{T} 1$ and $\mathrm{T} 2$ responses toward ELF is that ELF is the use of English from different native language. It is in line with Seidlhofer (2004), he argues that English is as communicative medium choice which is used among speakers of different first language. In this research, T2 also expressed that ELF is the way of communicating, similar with the term "communicative medium" proposed by Seidlhofer (2004). Some findings also highlighted that ELF is a tool of communication. In addition, the research by Nagy (2016) stated that ELF is not a language variant, but it is a communication medium. Based on the previous findings, the result of this research highlighted that teachers see ELF as the way of communicating between people from different native language, and they do not use English as native language in their country.

Indonesian Journal of EFL and Linguistics, 5(1), 2020 
Regarding to the features of English as Lingua Franca proposed by Seidlhofer (2004), teachers prominently indicated that those features really happened in their classroom interaction. They experienced those phenomena in the classroom. The first participant (T1) said that she experienced the features of ELF in classroom activities, and it is relatable. Similarly, the second participant (T2) argued that she experienced those phenomena in her students, and it does not matter as long as the mistakes will not change the fundament of the utterance itself. T1 utterance can be seen as follows:

"I think it is relatable. Actually, it really happens in my class. I experience those cases in my everyday teaching-learning activities."

Teacher 1

T2 explored her explanation as follows:

"Still OK. It's something that happens for learners. As long as the mistake will not change the fundament (change the meaning) of the sentence itself."

Teacher 2

Teachers are aware toward the features of English as Lingua Franca proposed by Seidlhofer (2004). T1 and T2 experienced those phenomena in their classroom interaction, and they accept that. In line with this research, Luo (2007) also stated that teachers in expanding circle, especially in Taiwan, are aware with the notion and feature of ELF, but they tend to use native norms rather than EFL features.

These findings support Seidlhofer (2004) concepts that the features of ELF are unproblematic in classroom interaction. Differently, Fazilatfar and Rahatloo (2018) revealed that Iranian teacher's trainee indicates ambivalence toward the existing of ELF norms. It was still debatable about the use of ELF features. In expanding circle setting, this research gave new perspective toward the existing of ELF norms. The result highlighted that although teachers are aware toward the existing of ELF features, they still accept those features easily.

After understanding the features of ELF, teachers were expected to give their future action in their classroom. The findings revealed that $\mathrm{T} 1$ had different perspective from T2. After knowing these features, T1 argued that she wants motivate their students to be braver using English and will help them to be more aware about the use of English in the world. Meanwhile, T2 will drill it over and over and use it every day. In contrary, T2 still considered those phenomena as mistakes. T1 expressed her opinion as follows:

"I think I will motivate my students to be braver in using English. I mean ... sometimes students are afraid to make mistake or are shy to talk in English because they think they cannot speak like native (British/American) so I will also present some varieties of English. I 
The Departure Point in Raising Teacher's Awareness

think it will help them to be more aware about the use of English in the world."

Teacher 1

Furthermore, T2 also gave her ideas as follows:

"Showing the correct example. Drill it over and over and use it everyday. Students will easily understand if the community (teachers and students) are doing it in the same way. Whenever there is a mistake, correct it on the spot (say the correct one) and practice it."

Teacher 2

Related to the features of ELF, T1 is contrary with T2. By understanding this feature, T1 will help students to be more aware toward ELF, differently T2 tends to use native speaker of English norms as the correct one. The result of this research is similar to the study by Fazilatfar and Rahatloo (2018) who stated that Iranian teachers have strong dependency toward Native Speaker (NS) norms. Similarly, Luo (2017) also revealed that teachers are aware of the notion of ELF, but they also adapt the prominence native speaker (NS) norms in English instruction. Other research by Nagy (2016) also found the same result that it was found that the finding of ELF research has great relevance to teaching EFL. Based on the teacher's reaction toward ELF features, T1 declared that she could accept the deviation of L1 norms, and will give corrective feedback later. Meanwhile, T2 had different perception. She said that she wanted to correct it on the spot.

Those result are similar with Asakereh et.al (2019) who stated that the teachers reflects ELF flexibility in their teaching, but they have big tendency to L1 norms. Similarly, it is in line with the result of Bayyurt et.al (2019) who revealed that although teachers were aware toward EFL, but they were doubtful about its implementation in their own teaching situation. This finding also indicates that T1 and T2 will try to apply it, but they are hesitant because of lack information regarding to English as Lingua Franca.

The spread of ELF term in expanding circle, especially in Indonesia, is still something new. The participants got the term "Lingua Franca" recently. T1 said that as long as the students can deliver the ideas well, the features by Seidlhofer (2004) is unproblematic. It also motivates students to be braver to speak English, because most of them feel afraid to speak English because of their grammar. Furthermore, T1 argued that she knew this term when she took master degree program. In addition, T2 also did not get this term in her bachelor program. T2 got this term from the exposure of the internet and also a platform for sharing with friends from different countries. Their utterances can be seen as follows:

"I knew that when I was in the university, especially when I took master degree."

Teacher 1

Indonesian Journal of EFL and Linguistics, 5(1), 2020 
Ambar Jati, Endang Fauziati and Sri Samiati Tarjana

"The exposure of internet and also communicating with other friends from different countries."

Teacher 2

Based on the discussion above, it can be inferred that both participants believe that the features of English as Lingua Franca (ELF) is unproblematic as long as it does not change the fundament of the utterances. In expanding circle, teachers were aware about the evolvement of English as Lingua Franca in the world. It also can motivate students to be more confident and braver to speak English. Therefore, the teachers also accept those terms. Unfortunately, some of the participants still have strong preferences toward Native Speaker norms.

\subsection{Teacher's Response toward the Realization of Lingua Franca Features}

Based on the result of the interview, briefly the participants could accept the features of English as Lingua Franca (hereafter, ELF). Through the unstructured questionnaire, the participants reacted in details toward the features of ELF by Seidlhofer. It deliberately portrayed the participants' responses. According to Seidlhofer (2004), the features of ELF can be involved as follows:

1. Omission of the third-person singular present tense morpheme $-s$;

2. Interchangeable use of the relative pronouns who and which;

3. Leaving out definite and indefinite articles;

4. Incorrect use of tags in questions;

5. Usage of redundant prepositions;

6. Frequent use of certain semantically-versatile, broad-spectrum verbs;

7. Using that-clauses instead of infinitive constructions, and

8. Overdoing explicitness.

Linked to lexico-grammar features proposed by Seidlhofer (2004), two participants respond the questionnaire in variety. Generally, the participants said that it is acceptable, but not desirable. From the questionnaire, they said that they would give corrective feedback and expect the future improvement. All participants did not choose the point unacceptable. It means that those features did not burden their students in delivering ideas or interacting to others. Similarly, the research by Curran and Chern (2017) conducted in expanding circle also supported the ELF features by valuing all varieties in English and willingness to study more about intercultural communication. Differently, the research by Fazilatfar and Rahatloo (2018) showed that some teachers are ambivalent toward ELF norms. So that, this research proposed new finding that the ELF norms were acceptable in expanding circle, especially Indonesia.

According to the questionnaire, T1 mentioned that the features such as, norm of dismissed prepositions, common use of definite semantically-versatile, broad-spectrum verbs, and overdoing explicitness are absolutely acceptable. Therefore, the corrective feedback may or may not be given in this case. The other features such as, lapse of the third-person singular of present simple, exchangeable use of the relative pronouns, 
lapse on definite and indefinite articles, inappropriate use of tags in questions, and employing that-clauses as an alternative of infinitive structures are acceptable but not desirable, consequently it would give corrective feedback and expect future improvement. Deciding these cases, T1 would not deduct the students' point in the term of speaking activity.

Different form T1, T2 also had different responses. T2 mentioned that two features of ELF lexico-grammar such as, lapse of the third-person singular of present simple and utilizing that-clauses as a replacement for of infinitive constructions are absolutely acceptable. In speaking activity, teachers could give tolerance in spite of their lack in grammar. Furthermore, the features such as, usage of dismissed prepositions, common use of certain semantically-versatile, broad-spectrum verbs, overdoing explicitness, substitutable use of the relative pronouns, missing out definite and indefinite articles, and improper use of tags in questions are acceptable but not desirable, consequently it would give corrective feedback and expect future improvement. Considering the case, $\mathrm{T} 2$ also would not deduct the students' point if their students uttered those features.

Based on those findings, it can be inferred that $\mathrm{T} 1$ and $\mathrm{T} 2$ supports the lexico-grammar features of ELF. In their speaking class, teachers give tolerance to the students who appearing these features in their classroom interaction. This findings strongly strengthen the statement that some expression in L1 norms that would be 'error', but it is actually unproblematic and no obstacle to gain successful interaction through ELF (Seidlhofer, 2006). From those findings, this research supported the lexico-grammar norms of ELF by Seidlhofer (2006). In line with this result, the research by Fazilatfar and Rahatloo (2018) was consistent with the existing literature in which uncertain perception toward the ELF norms among the pre-service and in-service teachers. Besides, this research gave new action from the teachers that teachers would not deduct the students' point because of ELF norms when their students delivered the idea well. This result also becomes the novelty of this research.

To sum up, teachers were aware toward the existence of lexico-grammar features in ELF. In general, teachers accept the students' utterance, and they will not deduct the point, if the students indicate deviance as ELF features in their classroom interaction. It will inspire other teachers to be more aware toward the wave of ELF, so that they could find and apply the relevancy of ELF in teaching learning process. Furthermore, Nagy (2016) also supported that the finding of ELF research has great relevance to teaching EFL.

\section{CONCLUSION}

Highlighting teacher's belief about English as Lingua Franca (ELF), the researchers draw the conclusion that teachers are aware toward the wave of English as Lingua Franca. Consequently, the lexico-grammar features of ELF are unproblematic as long as it does not change the fundament of the utterances. Although, the term ELF is quite new for the teachers, they strongly support the enhancement of ELF through giving opinion that those features are acceptable. They declared that these phenomena are 
often happened in their classroom, but it is not an obstacle to delivering ideas in speaking class. Although they support the viewpoint of ELF, the other teachers also strongly give preferences on L1 norms. They stated that when the students do mistakes as the features of ELF, they will correct it on the spot and drill the correct one. They also confess that they did not get the term ELF in their bachelor university. They just know the term English as Lingua Franca from master degree university, the exposure of the internet and also a platform for sharing with friends from different countries. This research hopefully gives insight about the atmosphere of ELF for all teachers in expanding circle, especially in Indonesia. The result of this research could be the starting point for teacher's trainees, novice teachers, and experienced teachers who do not know this term yet. For the next research, it will be more challenging to conduct the research on ELF in wider view, especially teaching method based on ELF concept. Hopefully, the integration of ELF in teaching and learning activities could give new strategy for teachers in teaching speaking, and the students will get the impact of learning English easily and comfortably.

\section{REFERENCES}

Asakereh, A., Yousofi, N., \& Weisi, H. (2019). ELF in the Iranian education system: Exploring teacher trainers' and pre-service/in-service English teachers' attitudes. Cogent Education, 6(1). https://doi.org/10.1080/2331186x.2019.1622625

Bayyurt, Y., Kurt, Y., Öztekin, E., Guerra, L., Cavalheiro, L., \& Pereira, R. (2019). English language teachers' awareness of english as a lingua franca in multilingual and multicultural contexts. Eurasian Journal of Applied Linguistics, 5(2), 185202. https://doi.org/10.32601/ejal.599230.

BELZ, J. A. (2002). "The myth of the deficient communicator". Language Teaching Research 6/1, 59-82.DOI : 10.1191/13621688021r097oa.

Bjorge, A. (2012). Expressing disagreement in ELF business negotiations: Theory and practice. Applied Linguistics, 33(4), 406-427. Borg, Simon. 2006. Teacher Cognition and Language Education. London: Continuum.

Borg, M. (2001). "Key concepts in ELT”, in Teacher's Belief, 55, 2: 186-188.

Crystal, D. (2003). English as a global language $\left(2^{\text {nd }} e d\right)$. Cambridge: Cambridge University Press.

Curran, J. E., \& Chern, C. lan. (2017). Pre-service English teachers' attitudes towards English as a lingua franca. Teaching and Teacher Education, 66, 137-146. https://doi.org/10.1016/j.tate.2017.04.007.

Farrell, T. (2011). Exploring the professional role identities of novice ESL teachers through reflective practice. Fuel and Energy Abstracts. 39. 10.1016/j.system.2011.01.012.

Fazilatfar, A. M. (2018). Iranian Teacher Trainees' Attitudes towards English as a Lingua Franca. (1), 29-60.

Firth, A. (1996). The discursive accomplishment of normality: on 'lingua franca' English and conversational analysis. Journal of Pragmatics, 26, 237-259. 
Görlach, M. (1990). The development of Standard Englishes. In: Görlach, Manfred (ed.). Studies in the History of the English Language. Heidelberg: Winter. 9-64.

Guba, E. G., \& Lincoln, Y. S. (1982). Epistemological and methodological bases of naturalistic inquiry. Educational Communication \& Technology Journal, 30(4), 233-252.

Jenkins, J. (2000). The Phonology of English as an International Language: New Model, New Norm. New York, NY: Oxford University Press.

Kachru, B.B. (1986) Non-native literatures in English as resource for language teaching, in C. J Brumfit and R.A Carter (eds), Literature and Language Teaching. Oxford: Oxford University Press, pp. 140-149.

Luo, W.-H. (2018). A study of Taiwanese university students' English use, learning goals and attitudes toward English as a lingua franca. Studies in Second Language Learning and Teaching, 8(4), 775-794. https://doi.org/10.14746/ssllt.2018.8.4.4.

Miles, M. B., Huberman, A. M., \& Saldana, J. (2018). Qualitative data analysis: A methods sourcebook (4th ed.). SAGE Publications.

Nagy, T. (2017). English as a lingua franca and its implications for teaching English as a foreign language. Acta Universitatis Sapientiae, Philologica, 8(2), 155-166. https://doi.org/10.1515/ausp-2016-0024.

Pajares, M. F. (1992) Teachers' beliefs and educational research: Cleaning up a messy construct, Review of Educational Research, 70:509-517.

Phillipson, R. (2008). Lingua franca of lingua frankensteina? English in European integration and globalisation. World Englishes, 27(2). 250-267.

Richards, J., C., \& Lockhart, C. (2005). Reflective practice in second language classroom. Cambridge: Cambridge University Press.

Seidlhofer, B. (2004). Research Perspectives on Teaching English as a Lingua Franca. Annual Review of Applied Linguistics, 24, 209-239.

Seidlhofer, B. (2006). English as a lingua franca in the Expanding Circle: what it isn't. In Rani Rubdy and Mario Saraceni (eds.), English in the World: Global Rules, Global Roles (pp. 40-50). London: Continuum.

Yin, R. K. (2018). Case study research and application: Designs and methods (6th ed.). Los Angeles: SAGE. 